the possibility of evolution and the transmutation of species. And from this idea sprang natural selection. It is illuminating and convincing to see how Darwin, in his intellectual maturing, changed from intelligent design to evolution.

Intelligent Thought is a book for scientists; that is, for those who see evolutionary biology as a science. If you are a creationist you will be unmoved; there is no point in looking at the evidence.

John Tyler Bonner is in the Department of Ecology and Evolutionary Biology, Princeton University, Princeton, New Jersey 08544, USA.

\title{
Diary of a weed
}

\section{Seed to Seed: The Secret Life of Plants \\ by Nicholas Harberd \\ Bloomsbury: 2006. 320 pp. £16.99, \$24.95}

\section{Anthony Trewavas}

Diaries are objects of intense fascination. Not only do they provide unique insight into the private thoughts and attitudes of the author, rarely conveyed by autobiography, but they can become important historical documents. Famous diarists such as Samuel Pepys in the seventeenth century and John Colville during the Second World War described the intimate workings of British government during periods of enormous social upheaval and war. Others, like the British politician Alan Clark, who consigned to their diary assessments of their political peers they would never voice in public, provide highly entertaining reading.

Diaries by working scientists are rare, so with the above thoughts in mind, I welcomed the chance to read Nick Harberd's contribution to the genre. Harberd is a plant molecular geneticist at the John Innes Institute in Norwich, and kept 'jottings' throughout 2004. Apart from the inevitable descriptions of seasonal changes in weather and wildlife and outlines of conversations with his two children, it slowly becomes apparent that the real subject of this diary is Arabidopsis, a weed with a very short life cycle (seed-to-seed) of some 4-6 weeks. These characteristics have made it the plant of choice for an enormous amount of gene identification and developmental analysis. Harberd uses the diary as a vehicle both to describe simple aspects of plant development and to structure his own research on Arabidopsis in 2004. The life cycle of a few wild specimens of Arabidopsis (in contrast to lab-grown versions) is also lovingly described - it ends when they provide a first-class meal for some roaming slugs!

Harberd records the thoughts, guesses, assessments, excitement, obsessions, publication problems and productive experiments that are the meat and drink of any experimental scientist. His significant achievement of 2004 was the identification and sequencing of the crucial rht (reduced height) gene. The 'green revolution' of the 1960s and 1970s resulted from the introduction of this gene into wheat and rice by Norman Borlaug. The resulting dwarf cereals had grain yields more than three times greater than their parents', and turned Mexico, China and India into net cereal exporters. An estimated 1 billion humans were saved from the savagery of slow starvation and premature death that some scientific Jeremiahs had long predicted as their inevitable fate.

The identification of this gene thus represents the final chapter in a story that vividly illustrates the value of technology in ameliorating human problems. We are technological animals. All human activities (including technology) have costs as well as benefits, but our capacity to rise to the challenge of complex problems is frankly what makes us human and makes living worthwhile. To deny this, to deny the value of the advance of science, as some currently do, is to deny our humanity.

Harberd's diary makes for easy and enjoyable reading for a plant biologist like myself, but I gradually began to wonder who its wider audience might actually be. Commentaries on seasonal changes in weather and nature form the basis of many published Edwardian diaries and are often better illustrated. The introduction makes clear that the author thinks the diary is written for non-scientists, but I was left wondering who, if any, of my non-scientific friends would make sense of it all. There is enormous interest in Britain in plants of all kinds, but from a gardening and horticultural perspective only. So a diary about a weed is unlikely to gain a sympathetic readership here. Despite the author's view of his readership, I think that other non-botanical scientists are the most likely audience and that many animal scientists and microbiologists would find pleasure in learning how the other half lives and works.

So is this diary instead a charm offensive from genetics, a subject often painted as based on grim-visaged determinism? Is it the velvet glove of the intensely human diarist hiding a genetical iron fist underneath? Harberd

\section{The body bared}

From the early

Renaissance on, our drive to discover, uncover and map the unknown has found rich pickings in the human body. Laying it bare from bone to skin became a mania among medics and artists alike, starting with Leonardo da Vinci and gaining momentum with the likes of Jacopo Berengario da Carpi, Andreas Vesalius, and later William Cheselden, John Hunter and today's digital modellers.

Human Anatomy: Depicting the Body from the Renaissance to Today by Benjamin A. Rifkin, Michael J. Ackerman and Judy Folkenberg (Thames \& Hudson, E17.95) dissects this history with elegance - and with the aid of 320 stunning illustrations that cover the gamut of styles, from Baroque surreality to the drily detached.

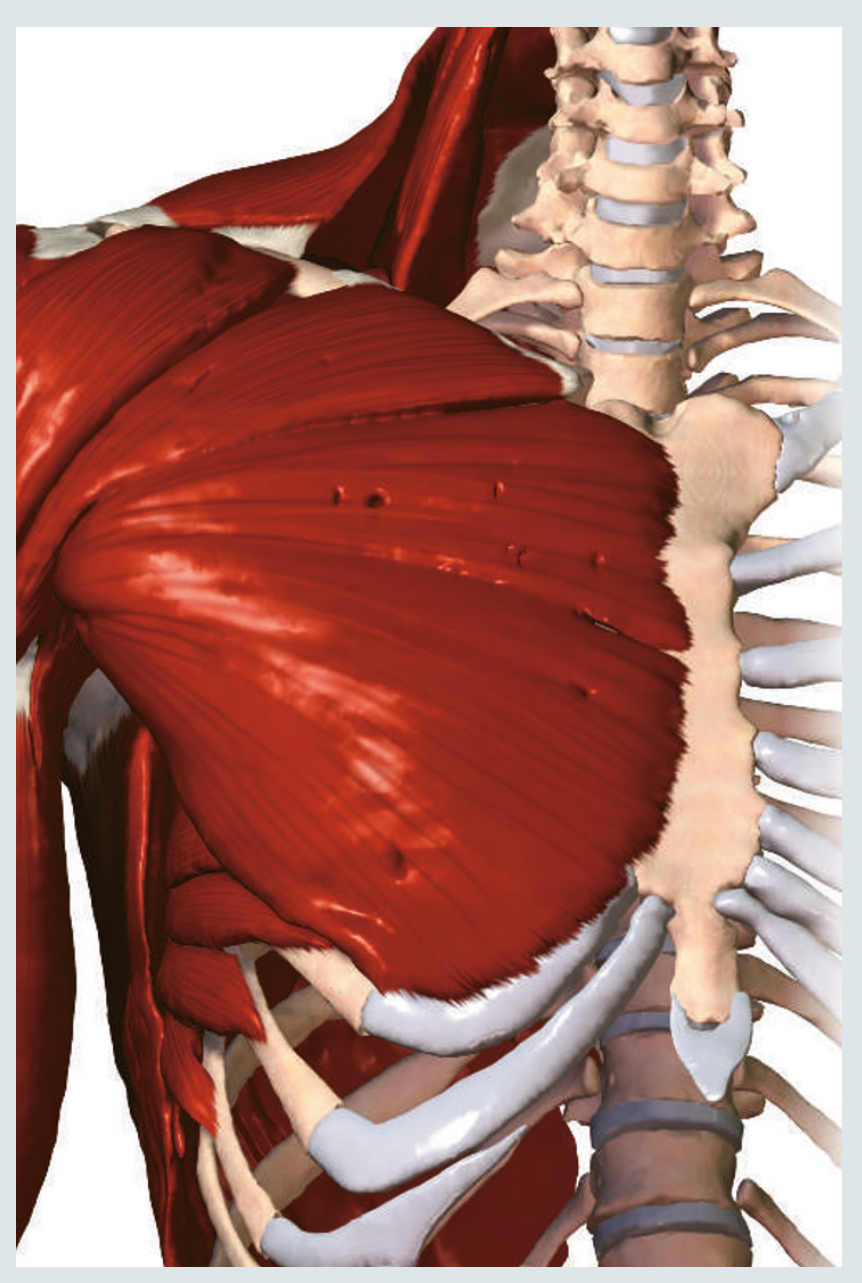

